\title{
Sinter Pot for Temperature Measurement of the Top Layer during and After the Ignition
}

\author{
Kenji TAIRA $^{1 / *}$ and Kyosuke HARA ${ }^{21}$ \\ 1) Advanced Technology Research Laboratories, Nippon Steel Corporation, 20-1 Shintomi, Futtsu, Chiba, $293-8511$ Japan. \\ 2) Process Research Laboratories, Nippon Steel Corporation, 20-1 Shintomi, Futtsu, Chiba, 293-8511 Japan.
}

(Received on February 17, 2020; accepted on April 22, 2020; J-STAGE Advance published date: June $11,2020)$

\begin{abstract}
For achieving high sinter yield and quality, various technologies are being implemented and developed to control the heat pattern during the sintering reaction. Further improvements in these technologies necessitate detailed time-course profiles of temperature at all sinter-bed heights; however, no technique has yet been reported for determining the temperature distribution in the top layers of the sinter bed at high spatial and time resolutions. Herein, detailed heat patterns in these layers were visualized by a newly developed pot test apparatus having $\sim 300-\mathrm{mm}$ sinter-bed height. The developed apparatus demonstrated the effect of ignition time on heat patterns during combustion and immediately after ignition. Ignition times of 30,60, and $90 \mathrm{~s}$ demonstrated that the high-temperature holding time increased with an increase in ignition time, and this effect is more evident in the top layer. All parameters, including high-temperature holding time, flue gas composition, and sinter yield, suggest that a longer ignition time intensified coke combustion in the top half layer. The developed technique to measure the temperature in the top layer will quantitatively clarify the effect of segregation or ignition condition on the heat pattern in the top layer.
\end{abstract}

KEY WORDS: sinter bed; ignition time; temperature distribution; heat pattern.

\section{Introduction}

The sintering reaction in Dwight-Lloyd (DL) machines, developed about a century ago, proceeds as a moving grate, fixed bed combustion. ${ }^{1)}$ The combustion therein propagates downwards after the ignition of the top layer via ignition burners. The combustion heat flows downstream and ignites the solid fuel particles in the sinter bed. After the sintering reaction is initiated, all the combustion reactions in the entire sinter bed autonomously proceed under continuous air flow. The conditions of the charged sinter bed and ignition have a profound effect on sinter quality and yield.

Continuous improvements of ignition burners increased the yields and energy efficiency of sintering machines. Steel companies independently develop and modify line, ${ }^{2)}$ multislit, ${ }^{3,4)}$ and surface combustion burners. ${ }^{5)}$ Some burners can optimize the $\mathrm{O}_{2}$ concentration in the flame by devising the fuel and air flow path. $\left.{ }^{6}\right)$ Proper $\mathrm{O}_{2}$ concentration in the flame ensures the combustion of solid fuels in the sinter bed and high energy efficiency of the burner. Although the continuous improvements of the ignition burner improved the combustion rate of coke or coal in the top layer of the sinter bed, this layer has a tendency to be of low yield. ${ }^{7)}$ To

\footnotetext{
* Corresponding author: E-mail: taira.e84.kenji@jp.nipponsteel.com
}

overcome this issue, various techniques have been developed and implemented in DL machines. ${ }^{5,8-11)}$ Of these, the most widely accepted technique is segregation of the sinter mixture, wherein an intensified sifting feeder is used to concentrate finer coke particles in the top layer. ${ }^{11,12)}$ The abundant coke supply in the top layer adds more heat and thus increases the yields. Furthermore, the addition of powdered coke onto the top surface after ignition was also effective to improve the strength and reducibility of the sinter; ${ }^{13)}$ after the completion of the ignition, the powdered coke was ignited by the heat supply from the top surface, resulting in higher yields in the top layer. The heat emitted in the top layer flows downward, igniting coke or coal particles in the lower layer. Hence, the heat pattern of the top layer affects the quality and yields of the entire sinter bed, making its investigation a crucial matter.

To achieve higher yield and sinter quality, and thereby lesser $\mathrm{CO}_{2}$ emission, the segregation of the sinter mixture and ignition condition need to be further optimized. Detailed information on the temperature distribution in a sinter bed and its time variation will enable the quantitative assessment of the effect of each technology on the heat pattern in the top layer. Our previous study visualized the detailed temperature distribution during the combustion in the middle and bottom layers. ${ }^{14)}$ However, to date, a technique to 
experimentally determine the heat pattern in the top layer at high spatial and time resolutions has not been proposed.

In this study, a pot test apparatus was developed for temperature measurement in the top layer and time-course profiles of temperature distribution during the ignition and immediately after the ignition. Moreover, the strong relationship between ignition time and temperature distribution was demonstrated using the developed reactor and apparatus.

\section{Experimental}

\subsection{Pot Test Apparatus and Preparation for Tempera- ture Measurement in the Top Layer}

Our previous report experimentally visualized the detailed time-course profile of temperature distribution in the sinter bed, ${ }^{14)}$ wherein a thermocouple was vertically scanned to monitor the temperature at each position in the sinter bed. This study employs the same method but with different locations of an electric slider and a thermocouple. Figure 1 illustrates the pot test apparatus developed for temperature measurement in the top layer of the sinter bed. The apparatus was manufactured using a 319-mm-diameter steel pipe and 9-mm-thick steel plates. A sinter pot with an inner diameter of $284 \mathrm{~mm}$ and depth of $302 \mathrm{~mm}$ was used. An electric slider (Oriental motor, EAS series) equipped with a step motor was settled in the cabinet located at the bottom of the reactor. A 9-mm-thick grate was placed at the bottom of the sinter mixture. Moreover, glass-wool insulation sheets were placed on the inner wall of the filling space to achieve 10-mm-thick glass-wool insulation, and an empty space with $\sim 260$-mm diameter remained for filling the sinter mixture. An alumina tube (TRIO ceramics, PTO series), with inner and outer diameters of 1.2 and $1.8 \mathrm{~mm}$, respectively, and length of $440 \mathrm{~mm}$, was inserted along the central axis of the sinter pot from the bottom of the sinter bed through the hole on the ceiling of the cabinet. The gap between the hole and the alumina tube was sealed with heat-resistant clay. The determined positions of the slider and alumina tube allowed smooth movement of the thermocouple in the alumina tube. The thickness of the tube's wall was $0.3 \mathrm{~mm}$, and the diameter of the tube was smaller than the average diameter of the raw materials. The alumina tube was held perpendicular to the ground of the sinter pot using a piece of string. The upper-side hole of the alumina tube was covered by a piece of scotch tape, which was removed later before the ignition, to prevent clogging. The vacant space in the sinter pot was filled by the raw materials that were previously mixed using a granulating machine. The sinter-bed thickness was $\sim 300 \mathrm{~mm}$, including the $\sim 20$-mm return-ore layer. The blending ratio of the sinter mixture was determined following the previous studies. ${ }^{14,15)}$ The scotch tape attached on the hole was removed, and a high-temperaturetolerant type-K sheathed thermocouple (Okazaki Manufacturing, HOSKINS2300 series, outer diameter: $1.0 \mathrm{~mm}$, sheath length: $460 \mathrm{~mm}$ ) was inserted into the alumina tube from the bottom for vertical scanning. To control the thermocouple, its sleeve was fixed on a stage of the slider. This study uses the K-type thermocouples because $\mathrm{Pt}-\mathrm{Rh}$ sheathed R-type thermocouples are expensive and fragile. The thermocouple tip was held $20 \mathrm{~mm}$ away from the top surface until the start of ignition because the top surface moves downward by $\sim 20 \mathrm{~mm}$ during ignition owing to the shrinkage caused by the sintering reaction.

As observed in Fig. 1, the electric slider and thermocouple can move without interference from the ignition burner. Therefore, the temperature in the sinter bed can be monitored by the thermocouple during ignition by the burner. The gas flow path is indicated by arrows in Fig. 1 . The gap between the bottom of the sinter bed and ceiling of the cabinet for the electric slider was $82 \mathrm{~mm}$. Here, the pressure loss caused by such a large space was considered negligible under the employed test conditions. It is notable that the interior of the alumina tube was not connected to the vacuum region and remained at atmospheric pressure (Appendix). Therefore, the gas flow through the alumina tube during the measurement was negligible.

\subsection{Pot Tests for the Temperature Measurements in the Top Layer}

For temperature measurement in the top layer, air flow of $2000 \mathrm{~L} / \mathrm{min}$ was first initiated. Next, the top surface of the raw materials was ignited for $30 \mathrm{~s}, 60 \mathrm{~s}$, or $90 \mathrm{~s}$ using the burner fueled by liquefied petroleum gas (LPG) and air at 75 and $2300 \mathrm{~L} / \mathrm{min}$, respectively. The electric slider was being cooled with a spot cooler throughout the experiments to avoid overheating of it. The concentrations of $\mathrm{O}_{2}$, $\mathrm{CO}_{2}$, and $\mathrm{CO}$ in the exhaust gas were recorded using a gas analyzer (SHIMADZU, CLM-108 and URA-208) until the completion of the sintering process. The gas flow rate was maintained at $2000 \mathrm{~L} / \mathrm{min}$ throughout the sintering process by controlling the negative pressure below the sinter bed. The flow rate was determined following the time variation of the flow rate during the pot test of the 600 -mm-thick sinter bed; the flow rate was approximately $2000 \mathrm{~L} / \mathrm{min}$ when the combustion proceeded to the top $300 \mathrm{~mm}$ layer. The monitored temperature values were recorded by a data logger (T\&D, MCR-4TC) every tenth of a second. The scanning of the thermocouple started $30 \mathrm{~s}$ after the start of the ignition. Before starting the scanning, the tip of the thermocouple was kept at $280 \mathrm{~mm}$ from the grate, $20 \mathrm{~mm}$ away from the initial top surface, because the top surface went down by $\sim 20 \mathrm{~mm}$ after the ignition; the sintering reaction caused by the burner frame led to the shrinkage of the top layer during the ignition. The scan rate was 3.0 and 5.0 $\mathrm{mm} / \mathrm{s}$ for the upward and downward directions, respectively, following our previous report; ${ }^{14)}$ wherein the scanning rates of the thermocouple ensured the good accordance between the temperature values of the scanned thermocouple and those of the static thermocouples inserted from the side wall. The obtained data were analyzed with MATLAB to visualize the temperature distribution and its time variation. The analysis details are presented in our previous report. ${ }^{14)}$ In short, the temperature, monitored position, and time were plotted in a three-dimensional graph. Then, the plotted data points were interpolated and reconstructed as grid data at every $10 \mathrm{~s}$ and $2 \mathrm{~mm}$. After completion of the sintering process, the obtained sinter cake was divided into top- and bottom-half layers and each layer was subjected to a shutter test and sieve classification. As for the 30-s ignition condition, the whole sinter cake was subjected to the tests because the sinter cake was too weak to be divided into the two layers. The sinter yields were calculated as the ratio of 


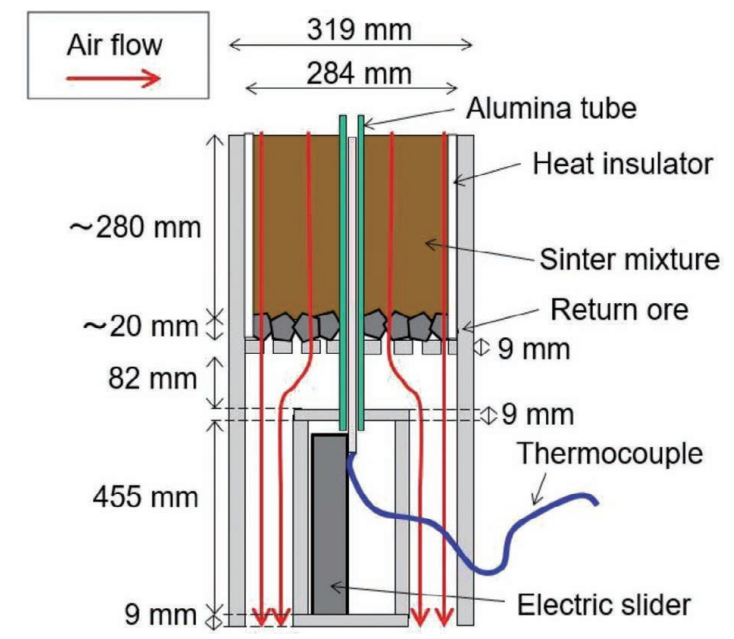

Fig. 1. Schematics of the pot test for temperature measurements. Lifting gears are not shown.

Table 1. Blending ratio of the raw materials for the pot test.

\begin{tabular}{cc}
\hline Raw material & Ratio (wt\%) \\
\hline Iron ore & 68.92 \\
Limestone & 11.86 \\
Olivine & 0.42 \\
Quicklime & 0.84 \\
Return ore & 12.53 \\
Coke & 3.93 \\
Dolomite & 1.50 \\
\hline Total & 100 \\
\hline
\end{tabular}

the sinter grains with diameters larger than $5 \mathrm{~mm}$. Here, the amount of return ore was subtracted from the yields. The entire procedure was performed twice for each ignition time to confirm the reproducibility of the pot test.

\section{Results and Discussion}

\subsection{Temperature Distribution at Various Ignition Times}

A series of temperature measurements illustrated the temperature distribution under various combustion conditions. As shown in Figs. 2-4, the temperature at $280 \mathrm{~mm}$, the top surface position after the ignition, increased with increase in the ignition time. The temperature at $280 \mathrm{~mm}$ reached higher than $1200^{\circ} \mathrm{C}$ during 90 -s ignition (Fig. 4), whereas it remained approximately $800^{\circ} \mathrm{C}$ during 30 -s ignition (Fig. 2). Meanwhile, the flame front position during ignition was independent of the ignition time and remained approximately at $260 \mathrm{~mm}$, indicating that the flame front remained practically motionless during ignition by the burner. This phenomenon was attributed to four factors. (1) The peak temperature was limited by the melt formation. The temperature at 280 $\mathrm{mm}$ does not increase linearly with the ignition time; the peak temperature remains lower than $1200^{\circ} \mathrm{C}$ even after the 90 -s ignition. Moreover, calcium oxide and iron oxide react to form calcium ferrites of low melting point $\left(\sim 1200^{\circ} \mathrm{C}\right) .{ }^{16,17)}$ On initiation of melt formation, the heat from the burner forms more melt in the surface layer instead of igniting more

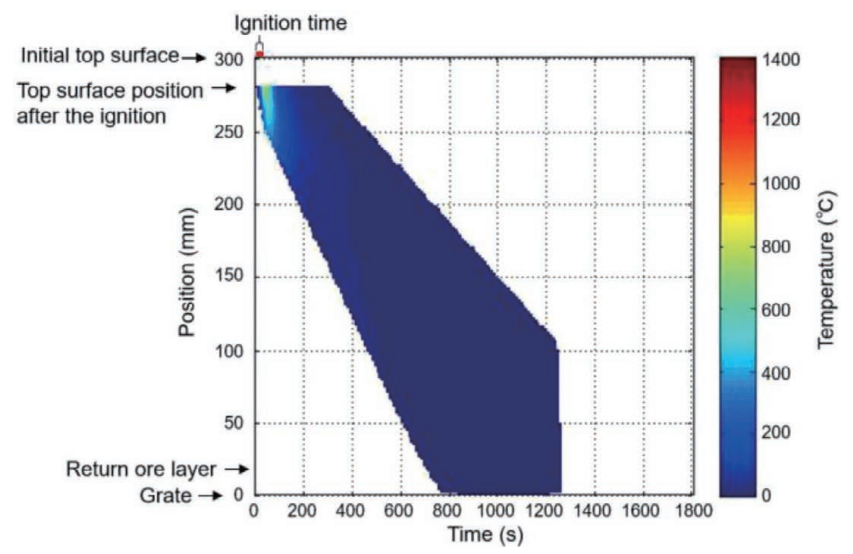

Fig. 2. Temperature measurement result for 30-s ignition.

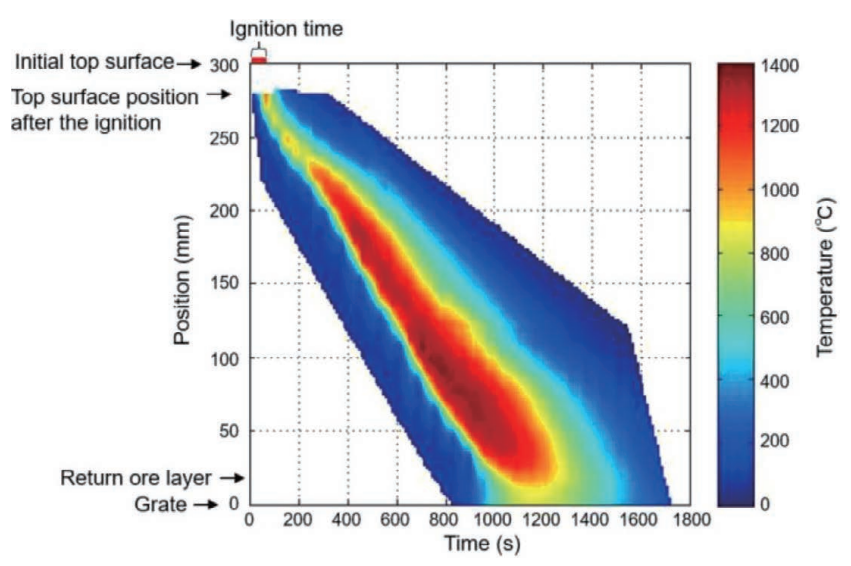

Fig. 3. Temperature measurement result for 60 -s ignition.

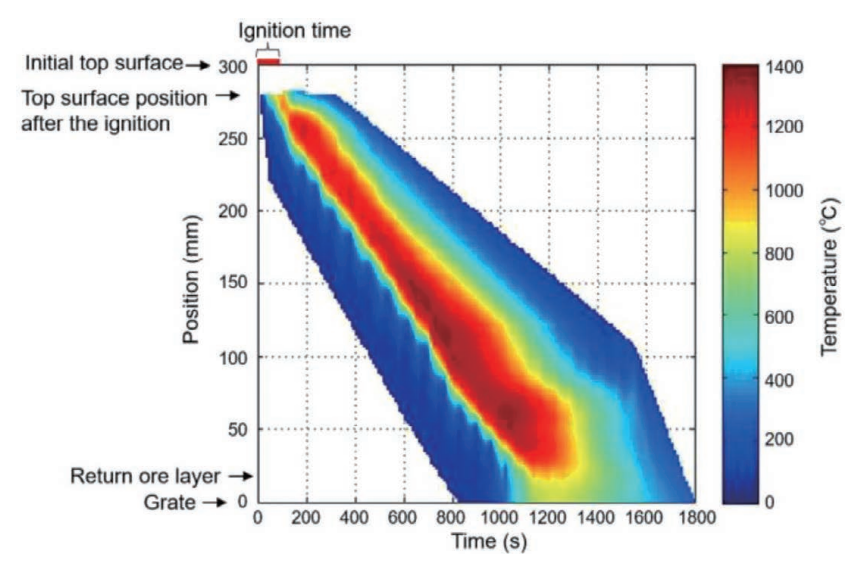

Fig. 4. Temperature measurement result for 90-s ignition.

coke particles in the lower layer. (2) The coke particles near the surface was consumed during ignition. Therefore, heat emission near the surface due to coke combustion gradually decreased with the increase in the ignition time. This phenomenon also limits the maximum temperature near the surface. This assumption was supported by the temperature during and after 90-s ignition. As shown in Fig. 4, from 280 to $270 \mathrm{~mm}$, the temperature decreased immediately after ignition for $90 \mathrm{~s}$. This suggests that coke in the layer completed combustion during ignition. (3) The inhomogeneous flow of gas owing to the sintering reaction. A small gap of several $\mathrm{mm}$ in width was observed between the sinter and wall after ignition, causing a small pressure loss near the 
wall of the pot. ${ }^{18,19)}$ The temperature measurement results suggest a melt formation around the central axis of the sinter bed. The pressure loss owing to this melt formation caused lower flow rate around the central axis, thus resulting in lower flame front speed (FFS) during ignition. ${ }^{20)}$ (4) The $\mathrm{O}_{2}$ consumption in the flame of the ignition burner. The LPG burner consumes the $\mathrm{O}_{2}$ in the inlet air, which decreases the $\mathrm{O}_{2}$ concentration and delays the ignition at the flame front.

The heat emitted in the top layer was transferred to and accumulated in the lower layer, reportedly leading to its higher temperature. ${ }^{711,12)}$ Therefore, the temperature during the combustion in the top layer affects the temperature in the lower layers. Figures 2-4 clearly demonstrate the dependence of the entire heat pattern on the ignition time. Ignition for $30 \mathrm{~s}$ failed to ignite the coal particles in the top layer. The peak temperature observed during the 30 -s ignition was $\sim 800^{\circ} \mathrm{C}$, which is higher than the ignition temperature of coke particles, i.e., $\sim 600^{\circ} \mathrm{C}$. However, the top surface is exposed to the cold ambient air and cooled down immediately. This situation led to the extinguishment of the coke combustion in the top layer immediately after the ignition. Contrary, the result for the 60-s ignition is clearly in good accordance with the general tendency of the heat pattern; the peak temperature increased, and the high-temperature holding time was extended with the downward propagation of the flame front (Fig. 2). In the top $50 \mathrm{~mm}$ of the sinter bed (from 280 to $230 \mathrm{~mm}$ in Fig. 3), the peak temperature remained lower than $1000^{\circ} \mathrm{C}$. Meanwhile, the peak temperature exceeded $1200^{\circ} \mathrm{C}$ at $\sim 220 \mathrm{~mm}$ from the bottom of the sinter bed and increased owing to the combustion heat emitted in the layer (Fig. 3). The accumulation of heat increased the temperature in the sinter bed and ensured melt formation in the lower layer. The 90-s ignition further increased the temperature and the high-temperature holding time. The temperature at $280 \mathrm{~mm}$ was higher than that for the $60-\mathrm{s}$ ignition. A layer with temperature higher than $1200^{\circ} \mathrm{C}$ was observed even at $260 \mathrm{~mm}$. The high-temperature holding time was extended in the lower layer accordingly. The effect of ignition time on the high-temperature holding time is quantitatively demonstrated in Fig. 5. At the all position in the sinter bed other than the bottom part (from 2 to $40 \mathrm{~mm}$ in Fig. 5), the 90-s ignition led to longer holding time than for the 60-s and 30-s ignitions. In addition, the holding time showed a tendency to extend as the position decreased. This result also demonstrates the effect of ignition time on the entire heat pattern during the combustion. The discrepancy in the bottom part, i.e., from 2 to $40 \mathrm{~mm}$, from the overall tendency is discussed in Section 3.3.

The yields of the sinter for the three ignition times are listed in Table 2. The 30-s ignition condition led no yields in the bottom layer, as the 30-s ignition failed to ignite the coke in the sinter bed. The sinter was formed only on the surface directly heated by burner during ignition. Meanwhile, the sinter yields increased steadily with the increase in the ignition time. The 90-s ignition had the highest yields for both the topand bottom-half layers, but the difference was more significant in the top layer. The 90 -s ignition obtained a yield of $64.3 \%$, whereas the 60 -s ignition obtained a yield of only $42.3 \%$. This result matches the time-course profile of the temperature and flue gas composition (Fig. 5). The high-temperature holding time in the top layer increased as the ignition time increased,

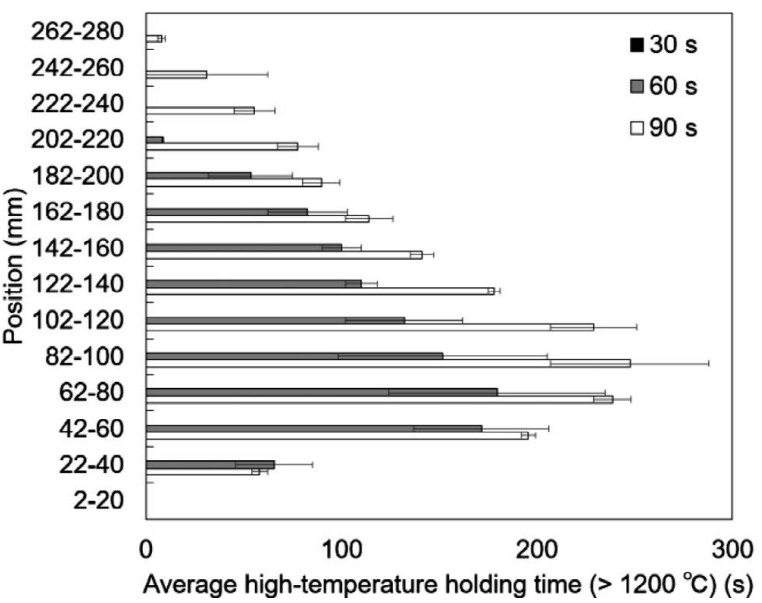

Fig. 5. Average temperature holding time above $1200^{\circ} \mathrm{C}$ at each layer under the 30-, 60-, and 90-s ignition conditions. The layer from 0 to $20 \mathrm{~mm}$ corresponds to the return-ore layer. The edges of the error bars correspond to the values of the first and second tests.

Table 2. Yields for the top and bottom halves of the sinter cake. The two values in the parenthesis are the yields for the first and the second tests. As for the ignition time of $30 \mathrm{~s}$, the yield was attributed to the top half layer since the bottom half layer remained the wet raw material after the reaction.

\begin{tabular}{ccc}
\hline Ignition time $(\mathrm{s})$ & Top half $(\%)$ & Bottom half $(\%)$ \\
\hline 30 & $25.6(23.6,27.4)$ & $0(0,0)$ \\
60 & $42.3(46.4,38.1)$ & $72.6(71.5,73.6)$ \\
90 & $64.3(65.3,63.3)$ & $76.9(77.0,76.7)$ \\
\hline
\end{tabular}

resulting in higher yields for a longer ignition time.

\subsection{Relation between Ignition Time and Flue Gas}

The plausibility of the temperature measurement results in Figs. 2-4 was assessed by the flue gas composition during the combustion. Figure 6(a) plots the $\mathrm{CO}_{2}$ concentration of the flue gas. During ignition, the $\mathrm{CO}_{2}$ concentration increased with increasing ignition time. The $\mathrm{CO}_{2}$ concentration of flue gas increased to $\sim 9 \%$ under the 30 -s ignition condition, whereas it reached $\sim 14 \%$ under the 60 - or 90 -s ignition condition (Fig. 6(a)). These results suggest that the 30 -s ignition failed to effectively ignite coke particles in the sinter mixture. In fact, $\mathrm{CO}_{2}$ emission halted immediately after the 30-s ignition. This assumption is in accordance with the temperature measurement results in Fig. 2, wherein the high-temperature layer did not proceed downward.

The flue gas composition also rationalizes the difference in the temperature between 60-s ignition and 90-s ignition. On comparing the flue gas compositions for the 60-s ignition and 90-s ignition, it was found that the $\mathrm{CO}_{2}$ concentration increased with the increase in the ignition time (Fig. 6(a)). At approximately $200 \mathrm{~s}$, the $\mathrm{CO}_{2}$ concentration is apparently higher for the 90-s ignition than for the 60-s ignition, suggesting the more intense combustion for the 90-s ignition; the $\mathrm{CO}_{2}$ concentration dropped to $\sim 7 \%$ at $200 \mathrm{~s}$ after the 60 -s ignition while the concentration remained higher than $8 \%$ after the 90 -s ignition. The $\mathrm{O}_{2}$ concentration was lower for the 90-s ignition than for the 60-s ignition at approximately $200 \mathrm{~s}$, also suggesting more intense combustion for 

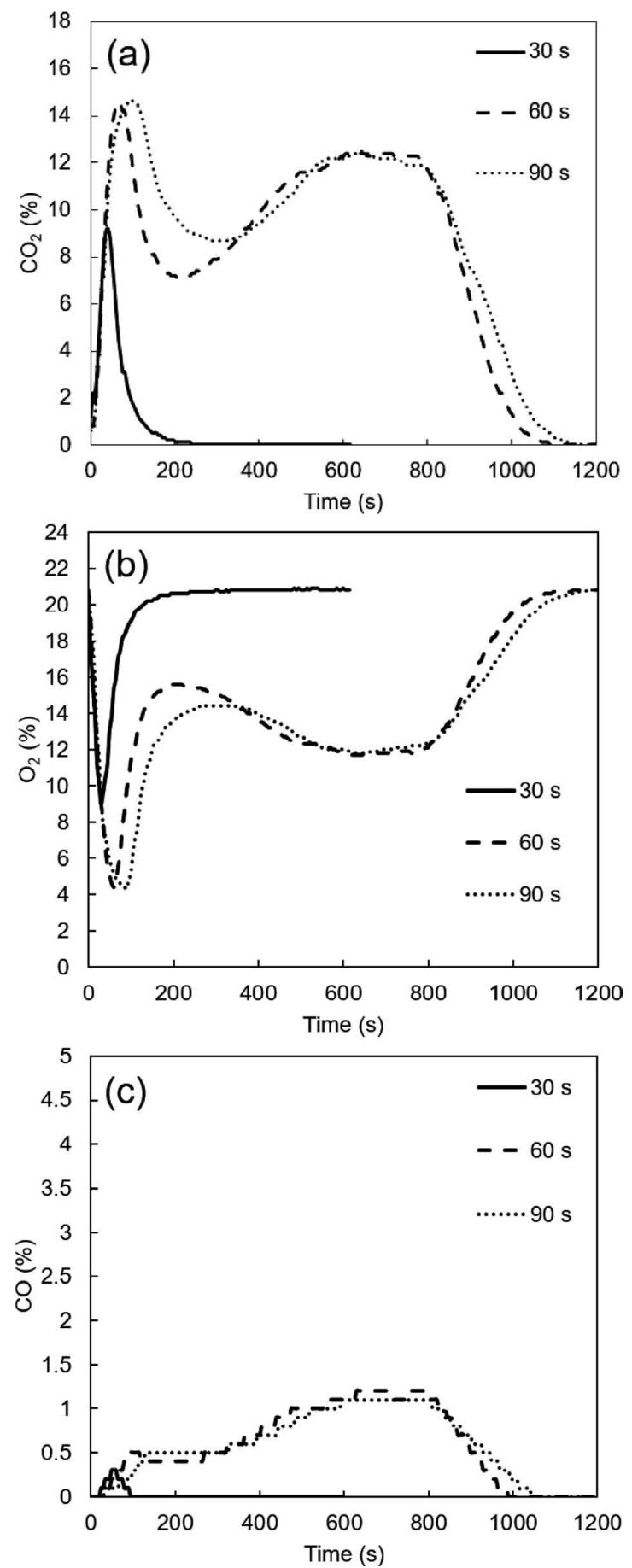

Fig. 6. Composition of the flue gas for pot tests (a) $\mathrm{CO}_{2}$, (b) $\mathrm{O}_{2}$, and (c) $\mathrm{CO}$.

the 90-s ignition than for 60-s ignition (Fig. 6(b)). These results are in good agreement with the temperature measurement results in Figs. 3 and 4; the peak temperatures at approximately $200 \mathrm{~s}$ were $1291^{\circ} \mathrm{C}$ and $1137^{\circ} \mathrm{C}$ for the 90 -s ignition and for the 60-s ignition, respectively. This result also suggests that the coke particles underwent more intense combustion after the 90 -s ignition than after the 60-s ignition owing to the abundant heat supply from the upper layer. As discussed above, the flue gas composition is in good accordance with the temperature variation during the combustion, suggesting the plausibility of the measurement technique.

\subsection{Validity of the Obtained Data}

The plausibility of the measurement technique of this

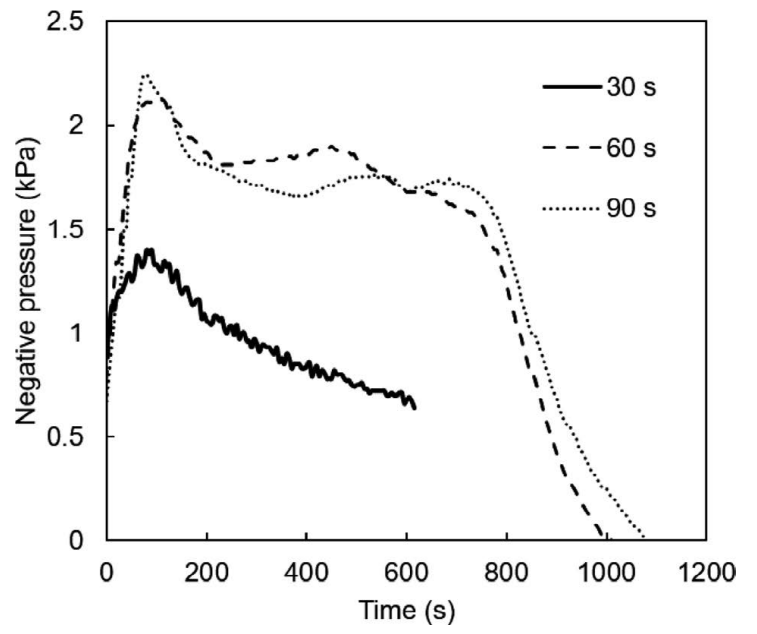

Fig. 7. Negative pressure below the sinter bed during the reaction.

study was supported by the temperature measurement results, yield, and the flue gas composition. The longer ignition time ensured efficient combustion of coke particles in the sinter bed and the longer high-temperature holding time. In this section, a few points are discussed for better understanding of the validity of the obtained data.

First is the temperature of the bottom layer. As shown in Fig. 5, the error bar of the holding time in the bottom layer, i.e., 100 to $2 \mathrm{~mm}$, is larger than those of the layer from 280 to $102 \mathrm{~mm}$. For the layer from 80 to $2 \mathrm{~mm}$, the edge of error bar for the 60-s ignition surpassed that of 90-s ignition. This tendency was attributed to the inhomogeneity of the flame front speed. Reportedly, the value of FFS tends to be larger near the inner wall of the sinter pot than that around the center of the pot. ${ }^{18,19)}$ This tendency causes the flame front to reach the grate near the inner wall of the sinter pot earlier than that around the center. This assumption was supported by the experimental results. The negative pressure started dropping at $800 \mathrm{~s}$ (Fig. 7), suggesting the burn-through at some position in the sinter bed. The acute decrease of $\mathrm{CO}_{2}$ concentration at $800 \mathrm{~s}$ also suggests the completion of the combustion and the burn-through at some position (Fig. 6(a)). In contrast, the flame front did not reach the grate near the central axis of the sinter bed; the flame front remained to be around $70 \mathrm{~mm}$ at $800 \mathrm{~s}$ in Figs. 3 and 4. This result means the burn-through did not proceed near the central axis at $800 \mathrm{~s}$. These results suggest that the burn-through occurred at the positions other than the central axis, that is, near the wall. Therefore, we consider that burn-through near the wall causes inhomogeneous gas flow in the layer from 80 to $2 \mathrm{~mm}$, and thereby, deforms the heat patterns; a part of the sinter bed received insufficient air supply owing to selective air flow near the wall. Therefore, the temperature data near the bottom of the sinter bed should be discussed sparingly. To overcome this issue, increasing the thickness of the sinter bed would be effective.

Second is the reproducibility of the temperature data. This study uses only one thermocouple for each measurement. This means that the method only obtains the temperature near the central axis of the sinter bed. Meanwhile, the sinter bed is unavoidably inhomogeneous. The coke particles are distributed in the sinter mixture. The sintering reaction causes the formation of crack in the sinter bed and inhomogeneities in the gas flow during reactions. Therefore, it 
would be better to conduct the measurement more than once to verify the validity of the temperature data.

\subsection{Further Application of the Proposed Temperature Measurement Technique}

All the results presented in 3.1 and 3.2 suggest that the developed pot test enables the assessment of the time-course profile of temperature distribution and flue gas composition during ignition and combustion. The sinter yields of the top- and bottom-half layers were in good accordance with the high-temperature holing time of the corresponding layers. This technique quantitatively visualizes the effects of various technologies on the temperature of the top layer in a sinter bed. Several possible applications of the proposed technique are presented below.

Segregation of the sinter mixture is the most widely implemented technology to boost sinter yield and quality in the top layer, ${ }^{11,12)}$ wherein different sizes of raw materials as well as coke and coal are placed at different heights in the sinter bed. The segregation of magnetite fine was also reported to increase the melt formation and yield in the top layer. ${ }^{21)}$ The temperature measurement technique proposed in this study can be applied to quantitatively estimate the temperature distribution at a spatial resolution less than 10 $\mathrm{mm}$ and thus obtain the optimal distribution of the sinter mixture to achieve higher productivity in the top layer.

Various ignition burners are in service in DL machines. Moreover, side burners, line burners, ${ }^{2)}$ multi-slit burners, ${ }^{3,4)}$ and surface combustion burners ${ }^{5)}$ are independently developed for sinter machines. The parameters of flame, i.e., peak temperature and $\mathrm{O}_{2}$ concentration in the flame, of these burners affect the sinter yield and quality in the top layer. Therefore, detailed temperature measurements in the top layer are required to accelerate further improvements of ignition burners and their operating condition.

\section{Conclusions}

The detailed heat patterns in the top layers of a sinter bed were visualized by the newly developed pot test apparatus having 300-mm sinter-bed height. The developed apparatus quantitatively demonstrated the effect of ignition time on the heat patterns during combustion and immediately after the ignition. The temperature at $280 \mathrm{~mm}$ from the grate remained less than $800^{\circ} \mathrm{C}$ during the 30 -s ignition, whereas it reached higher than $1200^{\circ} \mathrm{C}$ during the 90 -s ignition. The temperature during the ignition affected the temperature immediately after the ignition. The 30-s ignition failed to ignite coke particles in the sinter bed and led to the extinguishment of the coke combustion. Meanwhile, the 60-s and 90-s ignition successfully ignited the coke particles in the sinter bed; the frame front proceeded downwards at different peak temperatures. The 90 -s ignition kept the peak temperature above $1200^{\circ} \mathrm{C}$ in the layer from 222 to $280 \mathrm{~mm}$ after the ignition, but the peak temperature did not exceed $1200^{\circ} \mathrm{C}$ until the frame front reached $\sim 220 \mathrm{~mm}$ after the 60-s ignition. The longer ignition time led to longer high-temperature holding time during the entire combustion, which resulted in the higher yields. The effect of ignition time was more evident in the top half layer. The flue gas composition also suggested the more intense combustion of coke particles in the top layer for the extended ignition time.

\section{REFERENCES}

1) Y. Okada: Tetsu-to-Hagané, 2 (1916), 585 (in Japanese). https://doi. org/10.2355/tetsutohagane1915.2.6 585

2) M. Saino, H. Takahashi, K. Tanaka, N. Hutagami and M. Nakamura: Tetsu-to-Hagané, 71 (1985), 1895 (in Japanese). https://doi.org/10.2355/tetsutohagane1955.71.16_1895

3) T. Suzuki: Tetsu-to-Hagané, 76 (1990), 807 (in Japanese). https://doi. org/10.2355/tetsutohagane1955.76.6 807

4) K. He and L. Wang: Renew. Sustain. Energy Rev., 70 (2017), 1022. https://doi.org/10.1016/j.rser.2016.12.007

5) A. Cores, L. F. Verdeja, S. Ferreira, Í. Ruiz-Bustinza, J. Mochón, J. I. Robla and C. González Gasca: DYNA, 82 (2015), 227. https://doi. org/10.15446/dyna.v82n190.44054

6) K. Hara, K. Iwata, Y. Horikawa and M. Yamada: Proc. Conf. Chugoku-Shikoku Branch, Vol. 2016.54, The Japan Society of Mechanical Engineers, Tokyo, (2016), 20 (in Japanese). https://doi. org/10.1299/jsmecs.2016.54.20

7) T. Kawaguchi and M. Matsumura: Tetsu-to-Hagané, 100 (2014), 148 (in Japanese). https://doi.org/10.2355/tetsutohagane.100.148

8) S. Machida, T. Higuchi, N. Oyama, H. Sato, K. Takeda, K. Yamashita and K. Tamura: ISIJ Int., 49 (2009), 667. https://doi. org/10.2355/isijinternational.49.667

9) N. Oyama, K. Igawa, K. Nushiro, M. Ida and N. Fujii: Tetsu-toHagané, 86 (2000), 309 (in Japanese). https://doi.org/10.2355/ tetsutohagane1955.86.5 309

10) L. Lu and O. Ishiyama: Miner. Process. Extr. Metall., 125 (2016), 132. https://doi.org/10.1080/03719553.2016.1165500

11) E. P. Honorato and V. Seshadri: Ironmaking Steelmaking, 35 (2008), 405. https://doi.org/10.1179/174328108X318374

12) L. Lu and O. Ishiyama: Iron Ore, Woodhead Publishing, Cambridge, UK, (2015), 395. https://doi.org/10.1016/B978-1-78242-156-6.00014-9

13) T. Kawaguchi: Method for Producing Sintered Ore Excellent in Reducibility and Resistance to Reduction Powdering, Japanese Patent JP2701472B2, (1998) (in Japanese).

14) K. Taira and M. Matsumura: ISIJ Int., 58 (2018), 808. https://doi. org/10.2355/isijinternational.ISIJINT-2017-636

15) K. Taira: Fuel, 236(2019), 244. https://doi.org/10.1016/j.fuel.2018.09.008

16) N. A. S. Webster, M. I. Pownceby and I. C. Madsen: ISIJ Int., 53 (2013), 1334. https://doi.org/10.2355/isijinternational.53.1334

17) M. Kimura and R. Murao: ISIJ Int., 53 (2013), 2047. https://doi. org/10.2355/isijinternational.53.2047

18) C. E. Loo and M. F. Hutchens: ISIJ Int., 43 (2003), 630. https://doi. org/10.2355/isijinternational.43.630

19) C. E. Loo and D. J. Wong: ISIJ Int., 45 (2005), 449. https://doi. org/10.2355/isijinternational.45.449

20) J. Zhao and C. E. Loo: Miner. Process. Extr. Metall., 125 (2016), 165. https://doi.org/10.1080/03719553.2016.1166565

21) Y. Iwami, T. Yamamoto, N. Oyama, H. Matsuno, N. Saito and K. Nakashima: Tetsu-to-Hagané, 103 (2017), 325 (in Japanese). https:// doi.org/10.2355/tetsutohagane.TETSU-2016-008

\section{Appendix}

The vacuum region of the pot test apparatus.

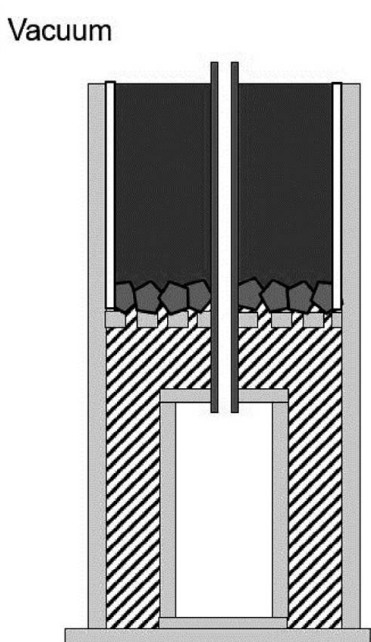

Fig. A1. The vacuum region of the pot test apparatus. 